\title{
The passepartout of Covid-19, Cytokine storm and Kounis syndrome: Pathophysiologic, Clinical and therapeutic considerations
}

Nicholas Kounis ${ }^{1}$, ioanna Koniari ${ }^{2}$, Stelios Asimakopoulos ${ }^{3}$, Ming-Yow Hung Hung ${ }^{4}$, Luca Saba $^{5}$, Vinu Arumugham ${ }^{6}$, Ricke Darrell O ${ }^{7}$, Mattia Jiovannini ${ }^{8}$, George Soufras ${ }^{1}$, Kenneth Nugent $^{9}$, Pierro Sestili ${ }^{10}$, Saad Javed Javed ${ }^{11}$, and Robert Malone ${ }^{12}$

${ }^{1}$ Affiliation not available

${ }^{2}$ University of Manchester Institute of Science and Technology

${ }^{3}$ University of Patrtas

${ }^{4}$ Taipei Medical University

${ }^{5}$ Universitaria di Cagliari

${ }^{6}$ Cisco Systems, Inc., San Jose, CA 95134,

${ }^{7}$ Massachusetts Institute of Technology

${ }^{8}$ Meyer Children's Hospital, Florence, Italy

${ }^{9}$ Texas Technical University Health Sciences Center

${ }^{10}$ Università degli Studi di Urbino

${ }^{11}$ University of Manchester Institute of Science and Technology Department of

Biomolecular Science

${ }^{12}$ Vaccines and Biotechnology, Scottsville, Virginia,

November 2, 2020

\begin{abstract}
Background: Coronavirus Disease 2019 (Covid-19), caused by severe acute respiratory syndrome coronavirus 2 (SARS-CoV-2), along with its cardiovascular, gastrointestinal, hematologic, mucocutaneous, respiratory, neurological, renal and testicular manifestations and further complications constitutes one of the deadliest pandemics in modern history. A common pathogenetic mechanism of these complications seems to be the Covid-19-induced excessive immune response of uncontrolled release of interleukins, chemokines, interferons, tumor necrosis factors and colony-stimulating factors, the so called cytokine storm syndrome. Severe anaphylactic reactions with profound hypotension or hypoxemia can be also associated with release of pro-inflammatory cytokines. Aim: Careful investigation for similarities in clinical manifestations and correlated multi-organ complications of Covid-19 with other viral infections including dengue and human immunodeficiency viruses together with the action of inflammatory cells inducing the Kounis syndrome could provide a better understanding on pathophysiolgy and trigger mechanisms, elucidating potential preventing and therapeutic strategies. Methods: A search was performed in Medline (via PubMed), for current literature on the pathophysiology, causality, clinical appearance, variance, prevention, and treatment of Covid-19, anaphylaxis with profuse hypotension and the Kounis anaphylaxis associated acute coronary syndrome. Results: Insights from research in allergy/anaphylaxis-associated cardiac syndromes and Covid-19, suggest that the same key immune cells are invollved in cardiovascular complications of Covid-19 and the anaphylaxis-associated Kounis syndrome. The myocardial injury in patients with Covid-19 has been attributed to coronary spasm, plaque rupture and microthrombi, hypoxic injury or cytokine storm and shares the same patho-physiology with the 3 clinical variants of Kounis syndrome. Conclusion: The patho-physiology, etiology, clinical manifestations and therapeutic approaches of the severe Covid-19 and their associations might be proved ben-
\end{abstract}


eficial for future treatments. Early immunological interventions targeting inflammatory markers that are predictive of worse disease outcome would be more beneficial than those blocking late-appearing cytokine related storm. Individualized, tailored to each patient treatment approach is required in Covid-19 cases

\section{Hosted file}

PAPER NEW 2020 IJCP FINAL revised.pdf available at https://authorea.com/users/372337/ articles/490428-the-passepartout-of-covid-19-cytokine-storm-and-kounis-syndromepathophysiologic-clinical-and-therapeutic-considerations

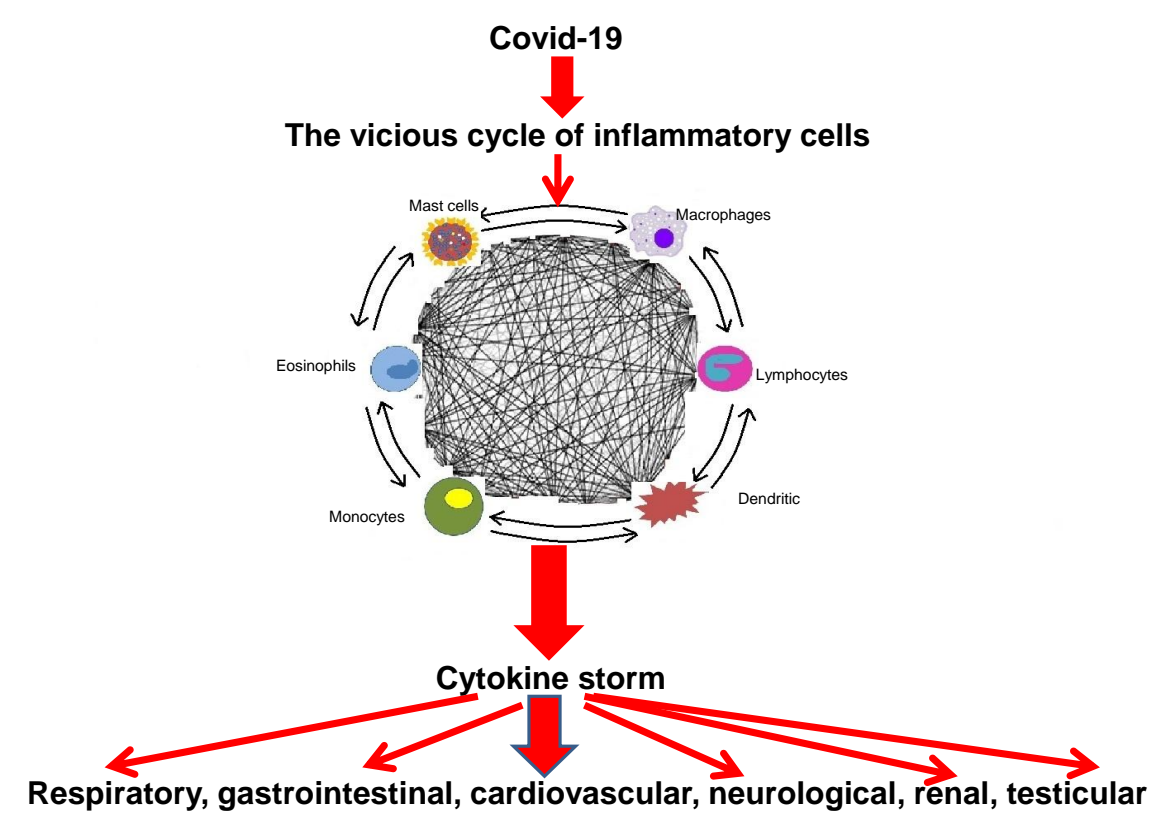

\section{Hosted file}

PAPER NEW 2020 IJCP Figure TITLE.pdf available at https://authorea.com/users/372337/articles/ 490428-the-passepartout-of-covid-19-cytokine-storm-and-kounis-syndrome-pathophysiologicclinical-and-therapeutic-considerations

\section{Hosted file}

PAPER NEW 2020 IJCP Table 1.pdf available at https://authorea.com/users/372337/articles/ 490428-the-passepartout-of-covid-19-cytokine-storm-and-kounis-syndrome-pathophysiologicclinical-and-therapeutic-considerations

\section{Hosted file}

PAPER NEW 2020 IJCP Table 2.pdf available at https://authorea.com/users/372337/articles/ 490428-the-passepartout-of-covid-19-cytokine-storm-and-kounis-syndrome-pathophysiologicclinical-and-therapeutic-considerations

\section{Hosted file}

PAPER NEW 2020 IJCP Table 3.pdf available at https://authorea.com/users/372337/articles/ 490428-the-passepartout-of-covid-19-cytokine-storm-and-kounis-syndrome-pathophysiologicclinical-and-therapeutic-considerations 


\section{Hosted file}

PAPER NEW 2020 IJCP Table 4.pdf available at https://authorea.com/users/372337/articles/ 490428-the-passepartout-of-covid-19-cytokine-storm-and-kounis-syndrome-pathophysiologicclinical-and-therapeutic-considerations 